\title{
Using Social Media to Determine the Affective and Cognitive Components of Tweets about Sunburn
}

\author{
Naomi Stekelenburg ${ }^{a}$ Caitlin Horsham ${ }^{a, b}$ Montana O'Hara ${ }^{a, b}$ \\ Monika Janda ${ }^{a}$ b \\ a School of Public Health and Social Work, Institute of Health and Biomedical Innovation, Queensland University of

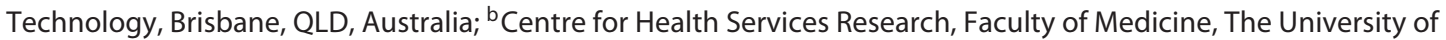 \\ Queensland, Brisbane, QLD, Australia
}

\section{Keywords}

Social media $\cdot$ Sunburn · Skin cancer · Twitter · Preventive health

\begin{abstract}
Background: The relationship between social media usage and the public's expressions of sunburn remains unexplored. This study is a content analysis of Twitter that was performed to identify the public's expressions, perceptions, and attitudes towards sunburn. Methods: Qualitative content analysis was conducted on tweets by Australian Twitter users during January 2007 and January 2016. Out of 2,000 tweets available, in-depth content analysis of 200 random tweets was performed. Results: Tweets in this study were categorised into 10 distinct themes, three of which were cognitive (fact based) and seven affective (emotional), while one was miscellaneous. Results reveal that tweets about sunburn overwhelmingly contained affective as opposed to cognitive components. In addition, the sentiments contained in the affective tweets were frequently positively (68.9\%) rather than negatively valanced (31.1\%). While humour was the most common theme ( $n=68$ tweets), many tweets also expressed a link between Australian national identity and sun-
\end{abstract}

karger@karger.com

www.karger.com/drm

Karger burn ( $n=25$ tweets). Conclusion: Many of the tweets analysed contained positive affective sentiments such as joy, rather than worry or concern, suggesting an avenue for further health promotion research.

(c) 2020 S. Karger AG, Basel

\section{Introduction}

Skin cancer is one of the most commonly diagnosed forms of cancer [1]. Australia and the USA have among the highest incidence of skin cancer in the world, with two in three Australians and one in five Americans being diagnosed with skin cancer before the age of 70 [2,3]. Skin cancer is largely preventable through adherence to behaviours that minimise skin exposure to the sun [4-6]. However, many Australians do not protect themselves sufficiently or consistently enough, and many still experience sunburn despite the use of sun protection $[7,8]$. This is of significant public health concern.

This article is part of the Nevi Article Series (c) 2020 S. Karger AG, Base
Prof Monika Janda

Centre for Health Services Research, The University of Queensland Building 33, Princess Alexandra Hospital Campus

Woolloongabba, QLD 4102 (Australia)

m.janda@uq.edu.au 
The underlying reasons for the continuing high prevalence of sunburn is unlikely to be a result of lack of cognitive awareness. A 2004 review of research by Stanton et al. [5] revealed that adults reported to be well aware of skin cancer, its risk factors, and methods of sun protection. However, knowledge about cancer prevention does not always equate with sun protection behaviours. Females, for instance, were found in multiple studies to have more knowledge of skin cancer prevention methods than males. However, females were also more likely to sunbathe deliberately, report a greater desire for a tan, and an increased perception that a tan equates with good health [5]. Therefore, it is likely that factors other than cognitive awareness play a role in the moderating of skin protection behaviours, including appearance norms and affective or emotional desires $[9,10]$.

Two paths of enquiry into preventative health generally may shed light on how people make decisions about sun protection [11]. Both of these paths of enquiry suggest that affective components are involved in decisions about health. Kahneman [12] posited that decision making is predicated on two pathways - the "intuitive" and "rational." The first pathway relies on quick-fire, emotional responses, the latter on reasoning, reflection and deliberate, effortful thought. Kahneman's conception of decision making deviates from standard behavioural models that are predicated on the assumption that individuals make rational choices. One theory from behavioural economics is called bounded willpower, which posits that people will often not make decisions that are in their best long-term interests due to a lack of self-control [13]. Accordingly, a behaviour that is fun now (shortterm benefit) will often be chosen rather than one that has a health benefit in the distant future. This has been shown to be the case in the instance of knowledge of sun damage versus sunscreen use in teens, a group with the least to be concerned about in terms of perceived immediate effects of sun damage [14].

Research using data posted on social media platforms such as Instagram, Snapchat, Facebook and Twitter may provide insight into how people frame their decisions about health in the social realm. Previous studies have shown that social media data can be used for surveillance to monitor and predict infectious disease outbreaks such as influenza and HIV outbreaks [15] and to explore public health topics including physical activity [16], body image [17], and mental health [18]. Twitter is increasingly being used to study attitudes to preventable disease caused by behaviours such as smoking [19] and tanning bed use [20,21]. Waring et al. [21] (2018) found tweets by tanners

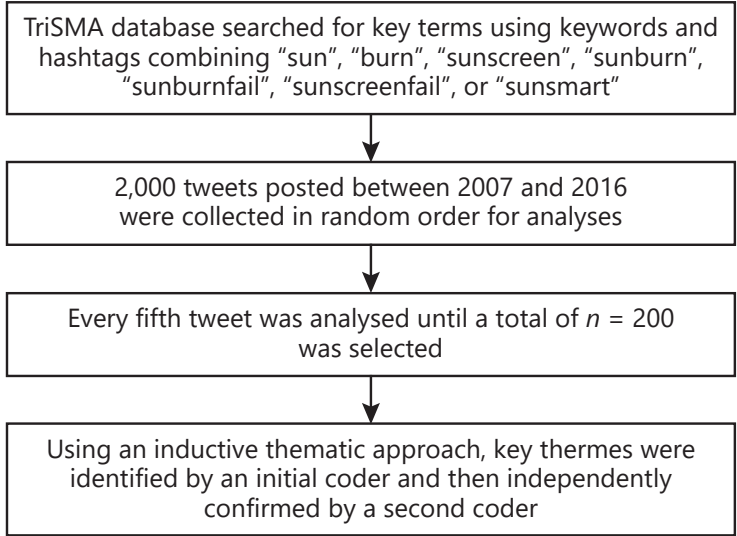

Fig. 1. Flowchart of Materials and Methods.

were mostly positive in sentiment (57\%) about how much they enjoy tanning, while only $29 \%$ were negative in sentiment. However, to date no study used a comprehensive set of tweets to study sunburn-related expressions.

This pilot study was undertaken to identify themes, topics, and pictures that Twitter users associated with the experience of sunburn, and to assess whether the tweets can be categorised into coherent themes, with assessment of the proportion that relay positive or negative valences.

\section{Materials and Methods}

For further details, see the online supplementary material (see www.karger.com/doi/10.1159/000506102 for all online suppl. material) (Fig. 1) [22].

\section{Results}

Of all tweets, 2\% (3/200) were not written in English. The remaining 98\% (197/200) of tweets were in English and were analysed. Out of the 197 tweets analysed, 84\% (166/197) were tweeted from urban areas, $14 \%$ were from regional areas, and 2\% (4/197) were unidentifiable (Table 1). Of the 197 tweets included in the analyses, 63 contained URL links to images uploaded with the tweets where gender could be obtained. Forty-one per cent (26/63) were female, and 30\% $(19 / 63)$ were male. The remaining URLs redirected to business pages $(n=4)$ and Twitter profiles which were no longer public $(n=14)$ (Table 1$)$. 
Table 1. Demographics of Twitter users

Tweets, $n(\%)$

$\begin{array}{lc}\text { Location the tweet was generated } & \\ \text { Urban } & \\ \text { Regional } & 166(84.3) \\ \text { Rural } & 27(13.7) \\ \text { Unknown } & - \\ & 4(2.0)\end{array}$

Gender retrieved from public user profiles that contained a URL $(n=63)$

Female

$26(41.3)$

Male

$19(30.2)$

Business page

$4(6.3)$

Broken link/profile no longer public

$14(22.2)$

${ }^{1}$ Geographic coding based on location type was provided by the TrISMA database.

\section{Content Analysis}

The 10 final categories included humour, shame, fear/ pain, worry, nationalistic sentiment, confusion, joy, statement of fact, future behaviour, and advice (Table 2).

The most commonly identified category was "humour" ( $n=68$ tweets). In tweets classified to fit this category, the use of emojis was common, as well as expressions of laughing at or about sunburn, or the way one looks if one is severely sunburned. In the "joy" category $(n=42)$ Twitter users commonly described the trade-off between having fun or doing an exciting activity such as attending an outdoor event and being sunburned. These tweets highlighted that sunburn is common in incidental or planned (fishing trip) outdoor activities and accepted as almost inevitable. In stark contrast, fear/pain tweets $(n=33)$ reported on the impact of sunburn on the tweeters' health and wellbeing. The "celebratory nationalism" category $(n=25)$ contained tweets that described sunburn as a national rite of passage, or simply being part of the Australian identity. A similar number of tweets were categorised to contain "statement of facts" $(n=24)$ with sunburn being mentioned almost in passing.

Of the identified categories, seven covered affective expressions, while three were conveying cognitive (factual) information. A greater number of tweets contained messages that were grouped under the affective $(n=196)$ than the cognitive categories $(n=36)$ (Table 3$)$.

Most of the affective tweets were rated to contain positive valence (68.9\%) (Table 4). In terms of the emotional valence of tweets, humour, joy, and nationalistic sentiment were positive, and shame/disgust, fear/pain, worry, and confusion were the tweets with negative valence. For the purpose of analysing the tweets about sunburn, nationalistic sentiment took on a celebratory, earnest, and affectionate tone and was therefore classed as positive.

\section{Image Analysis}

Of the 45 images available for analysis, 36\% (16/45) pertained to outdoor activities, including images taken at the beach, or whilst fishing, hiking, camping, skateboarding, or dog walking (online suppl. Table S1). A total of $22 \%(10 / 45)$ of images were taken in "selfie" style, depicting a self-portrait of sunburn with the face and/or chest being the most commonly sunburnt areas $(n=8)$. Images related to appreciation of nature, for example scenic photographs of the beach, a lake, or Australian bush landscape, made up $18 \%(8 / 45)$ of the images analysed. Images of lotions relating to sunburn relief, for example aloe vera gel $(n=3)$, and sunscreen bottles $(n=1)$, were also depicted. One image was a meme containing a movie reference where a character is dramatically applying a soothing lotion to a severe sunburn. Thirteen per cent $(6 / 45)$ of image URLs were miscellaneous and did not link to images where sunburn was identifiable.

\section{Discussion}

Social media use is increasing worldwide, especially among young people. Social media now plays an important role not only in the exchange of personal messages but as a source of unfiltered public opinion on healthrelated information and education [23]. Results from this study show Twitter users were more likely to express themselves about sunburn in positive affective, humorous, joyful, or national celebratory categories rather than negative affective or factual ways. Tweets about sunburn were posted during outdoor events that were perceived as joyful or fun. The image analysis revealed that most images were positively valanced such as outdoor activities or nature appreciation images depicted at the beach, hiking, or camping rather than the negative aspects of their sunburn (depicting the sunburn on their body).

Cultivation theory suggests that repeated exposure to media content results in normalisation of a behaviour by society [24]. Cultural shifts have led to a social preference for tanning and having tanned skin in Western cultures. In the social media landscape, a peer's behaviour can influence one's own behaviour [25]. For example, having friends who regularly use sunscreen is associated with sunscreen use and having friends who intentionally tan is associated with tanning levels [26]. A study in adolescents found that pic- 
Table 2. Major categories and exemplar tweets

\begin{tabular}{|c|c|c|}
\hline Humour & $\begin{array}{l}\text { laughter emoji, sarcasm, jokes, reference to laughter } \\
\text { (haha, lol, jokes); allusions to humorous motifs }\end{array}$ & $\begin{array}{l}\text { "Yep definitely got sunburn after this picture } \\
\text { hahaha" }\end{array}$ \\
\hline Joy & $\begin{array}{l}\text { Happy face/laughing emoji; expressed regret about pain of } \\
\text { sunburn but stated it was worth it for the fun; } \\
\text { described sunburn along with exciting event; associated } \\
\text { with something pleasurable }\end{array}$ & $\begin{array}{l}\text { "Awesome day out on the water and caught } \\
\text { dinner for tonight" }\end{array}$ \\
\hline $\begin{array}{l}\text { Celebratory } \\
\text { nationalism }\end{array}$ & $\begin{array}{l}\text { Connection between being sunburnt and being Australian } \\
\text { or in Australia; used colloquial Australian language in } \\
\text { description of being sunburnt e.g., "mate," sunburn used to } \\
\text { describe place "sunburnt landscapes" }\end{array}$ & $\begin{array}{l}\text { Use of the word "straya" (an abbreviation of } \\
\text { Australia) }\end{array}$ \\
\hline Shame & $\begin{array}{l}\text { Incorporated sense of being ugly after sunburn, sense of } \\
\text { embarrassment of being sunburnt }\end{array}$ & $\begin{array}{l}\text { "My face is peeling. Ugh. I hate sunburn! 3rd } \\
\text { time I’ve ever been sunburnt!!! Not okay man, } \\
\text { not okay" }\end{array}$ \\
\hline Worry & Sunburn as a threat; concerned for someone else & “@TMI_Australia how is ur sunburn today?” \\
\hline Confusion & $\begin{array}{l}\text { Expressed unexpected outcome; sunburn still occurred after } \\
\text { using sun protection }\end{array}$ & $\begin{array}{l}\text { "for once in my life I used sunscreen and I still } \\
\text { got sunburnt down the backs of my legs and } \\
\text { arms" }\end{array}$ \\
\hline Statement of fact & $\begin{array}{l}\text { Stated I am sunburn; often accompanied by a sense of } \\
\text { normality }\end{array}$ & $\begin{array}{l}\text { "I came home from summer vacay sunburned, } \\
\text { and now Melbourne is flooded so I'm } \\
\text { rearranging living rm furniture" }\end{array}$ \\
\hline Future behaviour & $\begin{array}{l}\text { Would not repeat behaviour; used sunburn event as a } \\
\text { prompt for future sun protection }\end{array}$ & $\begin{array}{l}\text { "My sunburn's now at that point where it's itchy } \\
\text { as fk, but hurts like hell to scratch" }\end{array}$ \\
\hline
\end{tabular}

Hashtags were removed from quotes to ensure participant confidentiality.

tures relating to tanning (such as viewing or posting pictures and liking or sharing content) on social media were significantly associated with more skin tone dissatisfaction, more sun exposure, and less frequent sun protection [9]. Messages communicated via social media channels can therefore significantly impact on how people may perceive health-related behaviours such as being sunburned and the perceived severity or normality of such an event.

Cancer organisations nationally and internationally have made attempts to use social media to encourage sun safety. This has led to humorous campaigns, for example, "Help a Dane abroad" by The Danish Cancer Society [27], and those that tried to present sun protection as a fashionable and desirable behaviour such as "Pretty shady" by the Cancer Institute NSW [28]. The National Council on
Skin Cancer Prevention in the United States created a public awareness campaign, "Don't Fry Day," to encourage sun safety [29]. The hashtag \#DontFryDay was used to track the conversations with more than 12 million impressions from individuals, health and nongovernment organisations, celebrities, and news organisations, among others [29]. Despite some of these campaigns being successful in reaching a wide audience, the authors identified that many individual users of the \#DontFryDay campaign were health professionals who may not engage in unsafe sun protection behaviour. The sheer volume and depth of personal social media messages that may convey a positive attitude towards being in the sun, tanning, or even sunburn according to the findings of this present study, creates a difficult environment for health promo- 
Table 3. Total numbers of tweeted sentiments according to neuropsychological categorisation (affective vs. cognitive)

\begin{tabular}{lc}
\hline & Tweets, $n$ \\
\hline Affective & 68 \\
Humour & 42 \\
Joy & 25 \\
Celebratory nationalism & 5 \\
Shame/disgust & 33 \\
Fear/pain & 14 \\
Worry & 9 \\
Confusion & $\mathbf{1 9 6}$ \\
\hline Total & 24 \\
\hline Cognitive & 4 \\
Statement of fact & 8 \\
Future behaviour & 36 \\
Advice & \\
\hline Total & \\
\hline
\end{tabular}

There were no limits to the number of themes that could be assigned to each tweet.

tion. These may be enhanced by the general tone of the platform itself and reaffirming "likes" or emojis. This was observed in our study of tweets, particularly in the "joy" category, which were specifically themed around the notion of having experienced a dismissible loss (sunburn) for a highly valuable pleasure (e.g., a concert, a day at the beach). This follows Kahneman's conception of decision making and "intuitive" responses.

Health promotion programs are commonly guided by the prevalent health behaviour theories, which assume that protective behaviours will be more likely if people feel an illness is serious, they are susceptible to it, and they have self-efficacy to conduct preventive behaviours. Programs rarely include concepts of national identity or cultural adaptation to environmental conditions. A unique aspect of this study, and a factor that has yet to be raised in the literature on sun protection in Australia, is the notion of celebrating national identity. Of particular interest was the frequency of references to Dorothy McKellar's poem My Country, the most well-known and often cited line being "I love a sunburnt country" [30]. Nationalistic tweets featuring McKellar's poem and other references such as \#Straya (an abbreviation of the word Australia) seemed to contain a celebratory acceptance of being sunburnt. It is as though the land and the individual merge and the notion of "loving" - not fearing or worrying about - sunburn becomes part of the expectation of

Social Media Tweets about Sunburn:

Affective and Cognitive Components
Table 4. Emotional valence of affective tweets $(n=196)$

\begin{tabular}{lc}
\hline & Tweets, $n(\%)$ \\
\hline Positive & \\
Humour & $68(34.7)$ \\
Joy & $42(21.4)$ \\
Celebratory nationalism & $25(12.8)$ \\
\hline Total & $\mathbf{1 3 5 ( 6 8 . 9 )}$ \\
\hline Negative & \\
Shame/disgust & $5(2.6)$ \\
Fear/pain & $33(16.8)$ \\
Worry & $14(7.1)$ \\
Confusion & $9(4.6)$ \\
\hline Total & $\mathbf{6 1 ( 3 1 . 1 )}$ \\
\hline
\end{tabular}

being Australian. Past studies have revealed an association between aspects of identity and health behaviour, but this specific strain of group belonging and with it the expectation of sunburn warrants further investigation. Health promotion campaigns may need to begin to rewrite narratives of what it means to be Australian in order to produce sustainable behavioural change.

While this study is one of the first to conduct an analyses of freely available social media messages related to sunburn and sun protection, it is limited by the analysis of only a comparatively small number of tweets. This study used the most common hashtags and keywords of Twitter posts regarding sunburn. However, it is likely that some relevant tweets may have been unintentionally missed in the datafiltering process such as tweets that use irony, sarcasm, or other descriptive terms to describe sunburn. The results indicate, however, that a larger and more sophisticated analysis encompassing several social media platforms will be required to understand the stream of messages to which people are exposed, many of which may contradict or counteract prevailing health promotion messages.

In conclusion, this study confirms the link between affect and sun exposure behaviour, highlights the presence of positive affect in the contextualisation of a current sunburn event, and is unique in its identification of a possible link between Australian national identity and the expectation of sunburn.

\section{Key Message}

Many of the sunburn tweets contained positive, affective sentiments such as joy, rather than concern. 


\section{Statement of Ethics}

This study was approved by the Queensland University of Technology Human Research Ethics Committee (approval No. 1700000325). No users were invited to participate as part of the Tracking Infrastructure for Social Media Analysis (TrISMA). Participants were those who had posted publicly on social media accounts. When quoting a tweet, tweets were slightly rephrased and mentions and hashtags were removed to prevent tweets from being identifiable.

\section{Disclosure Statement}

The authors have no conflicts of interest to declare.

\section{Funding Sources}

M.J. is funded by a TRIP Fellowship (APP1151021).

\section{Author Contributions}

All authors contributed to the study design. M.O'H. and N.S. retrieved the data from the TrISMA database. N.S. and C.H. conducted qualitative analysis. M.O'H. conducted image content analysis. All authors participated in the drafting and writing of the manuscript, contributed to the interpretation and critical revision of the manuscript, and gave final approval of this manuscript.

\section{References}

1 Apalla Z, Lallas A, Sotiriou E, Lazaridou E, Ioannides D. Epidemiological trends in skin cancer. Dermatol Pract Concept. 2017 Apr; 7(2):1-6.

2 Australian Institute of Health and Welfare (AIHW). Skin Cancer in Australia. Cat. no. CAN 96. Canberra: AIHW; 2016. Available from: https://www.aihw.gov.au/reports/cancer/skin-cancer-in-australia/contents/tableof-contents.

3 World Health Organisation (WHO). Skin cancers [cited 2018 September 7]. Available from: http://www.who.int/uv/faq/skincancer/en/index1.html

4 Koch S, Pettigrew S, Hollier LP, Slevin T, Strickland M, Minto C, et al. Trends in Australian adolescents' sun-protection behaviours: implications for health campaigns. Aust N Z J Public Health. 2016 Oct;40(5): $468-73$.

5 Stanton WR, Janda M, Baade PD, Anderson P. Primary prevention of skin cancer: a review of sun protection in Australia and internationally. Health Promot Int. 2004 Sep;19(3): 369-78.

6 US Department of Health Human Services. Reports of the Surgeon General. The Surgeon General's Call to Action to Prevent Skin Cancer. Washington (DC). Office of the Surgeon General (US); 2014. Available from: https:// www.ncbi.nlm.nih.gov/pubmed/25320835.

7 Dobbinson SJ, Jamsen K, Dixon HG, Spittal MJ, Lagerlund M, Lipscomb JE, et al. Assessing population-wide behaviour change: concordance of 10-year trends in self-reported and observed sun protection. Int J Public Health. 2014 Feb;59(1):157-66.

8 Cancer Council Australia. Almost half of Australians confused about sunscreen 2017 [cited 2018 Sep 7]. Available from: https:// www.cancer.org.au/content/pdf/News/MediaReleases/2017/20102017\%20MEDIA $\% 20$ RELEASE\%20-\%20Sunscreen\%20myths-FINAL.pdf\#_ga=2.141452210.1240745036. 1536284921-1417605416.1509083882
9 Mingoia J, Hutchinson AD, Gleaves DH, Corsini N, Wilson C. Use of social networking sites and associations with skin tone dissatisfaction, sun exposure, and sun protection in a sample of Australian adolescents. Psychol Health. 2017 Dec;32(12):1502-17.

10 Hutchinson AD, Prichard I, Ettridge K, Wilson C. Skin tone dissatisfaction, sun exposure, and sun protection in Australian adolescents. Int J Behav Med. 2015 Aug;22(4):435-42.

11 García-Romero MT, Geller AC, Kawachi I. Using behavioral economics to promote healthy behavior toward sun exposure in adolescents and young adults. Prev Med. 2015 Dec;81:184-8.

12 Kahneman D. Thinking, fast and slow. 1st ed. New York: Farrar, Straus and Giroux; 2011.

13 Thorgeirsson T, Kawachi I. Behavioral economics: merging psychology and economics for lifestyle interventions. Am J Prev Med. 2013 Feb;44(2):185-9.

14 Robinson JK, Rademaker AW, Sylvester JA, Cook B. Summer sun exposure: knowledge, attitudes, and behaviors of Midwest adolescents. Prev Med. 1997 May-Jun;26(3):364-72.

15 Paul MJ, Dredze M, Broniatowski D. Twitter improves influenza forecasting. PLoS Curr. 2014 Oct; $6: 6$.

16 Teodoro R, Naaman M, editors. Fitter with Twitter: understanding personal health and fitness activity in social media. Proceedings of the 7th International Conference on Weblogs and Social Media; 2013 July 8-11; Cambridge, MA, USA. Palo Alto: AAAI Press; 2013.

17 Fardouly J, Willburger BK, Vartanian LR. Instagram use and young women's body image concerns and self-objectification: testing mediational pathways. New Media Soc. 2018; 20(4):1380-95.

18 De Choudhury M, Kiciman E, Dredze M, Coppersmith G, Kumar M. Discovering shifts to suicidal ideation from mental health content in social media. Proc SIGCHI Conf Hum Factor Comput Syst. 2016;2016:2098-110.

19 Myslín M, Zhu SH, Chapman W, Conway M. Using Twitter to examine smoking behavior and perceptions of emerging tobacco products. J Med Internet Res. 2013 Aug;15(8):e174.

20 Falzone AE, Brindis CD, Chren MM, Junn A, Pagoto S, Wehner M, et al. Teens, tweets, and tanning beds: rethinking the use of social media for skin cancer prevention. Am J Prev Med. 2017;53(3S1):S86-s94.

21 Waring ME, Baker K, Peluso A, May CN, Pagoto SL. Content analysis of Twitter chatter about indoor tanning. Transl Behav Med. 2019 Jan 1;9(1):41-7.

22 Bruns A, Moon B, Münch F, Sadkowsky T. The Australian Twittersphere in 2016: mapping the follower/followee network. Soc Med Soc. 2017. Available from: https://doi. org/10.1177/2056305117748162

23 Bartlett C, Wurtz R. Twitter and public health. J Public Health Manag Pract. 2015 Jul-Aug; 21(4):375-83.

24 Gerbner G, Gross L, Morgan M. Growing up with television: cultivation processes. In: Bryant J, Zillman D, editors. Media effects: advances in theory and research. 2nd ed. Mahwah (NJ): Erlbaum; 2002. p. 43-67.

25 Jackson KM, Aiken LS. A psychosocial model of sun protection and sunbathing in young women: the impact of health beliefs, attitudes, norms, and self-efficacy for sun protection. Health Psychol. 2000 Sep;19(5):469-78.

26 Holman DM, Watson M. Correlates of intentional tanning among adolescents in the United States: a systematic review of the literature. JAdolescHealth.2013 May;52(5Suppl):S52-9.

27 The Danish Cancer Society. The Danish Sun Safety Campaign [cited 2018 August 31]. Available from: https://www.helpadane.com/.

28 Cancer Institute NSW. Pretty Shady 2016 [cited 2018 August 31]. Available from: http:// www.yourtimeinthesun.com/.

29 Nguyen JL, Heckman C, Perna F. Analysis of the Twitter "Don't Fry Day" Campaign. JAMA Dermatol. 2018 Aug;154(8):961-2.

30 McKellar D. My Country [cited 2019 August 31]. Available from: https://www.dorotheamackellar. com.au/archive/mycountry.htm. 